\title{
Prosthetic valve thrombosis in a tertiary cardiac centre
}

\author{
Anish Hirachan, ${ }^{1}$ Madhu Roka, ${ }^{2}$ Dipanker Prajapati, ${ }^{2}$ Chandra Mani Adhikari, ${ }^{2}$ Bishal K.C, ${ }^{1}$ \\ Manjila Basnet Khadka, ${ }^{2}$ Arun Maskey, ${ }^{2}$ Deewakar Sharma ${ }^{2}$
}

\author{
${ }^{1}$ Department of Cardiology, National Academy of Medical Sciences, Kathmandu \\ ${ }^{2}$ Department of Cardiology, Sahid Gangalal National Heart Centre, Bansbari, Kathmandu
}

Corresponding Author: Anish Hirachan

Department of Cardiology,

National Academy of Medical Sciences, Kathmandu, Nepal,

Email Address: hirachananish@gmail.com

\begin{abstract}
Background and Aims: Prosthetic valve thrombosis remains a major complication of valve replacement surgeries in Nepal. A number of patients present with thrombotic complications mainly due to poor anticoagulation status with irregular INR checkup at the remote areas of Nepal. Thrombolysis is the preferred method in the management of stuck valve patients due to financial issues. We aimed to retrospectively study the clinical profile and management trends of stuck prosthetic valve

Methods: : A one year retrospective data of 23 patients (Jan 2015 - Jan 2016) admitted with diagnosis of prosthetic valve thrombosis were studied. The demographic profile, clinical parameters and in hospital outcome were analysed.

Results: Out of 23 patients, majority were female $(52.2 \%)$ with the age group $13-49$ years $($ mean $=35)$. Sixteen patients $(69.6 \%)$ presented with INR value $<1.5$ at admission. Twenty patients $(86.9 \%)$ were thrombolysed with streptokinase while 3 patients ( $13.1 \%$ ) were subjected to treatment with tenecteplase. Valve thrombosis was most common at the mitral position $17(73.9 \%)$ patients. In hospital mortality was seen in $5(21.7 \%)$ patients and there were no major bleeding events or new stroke noted.

Conclusion: Majority of patients with prosthetic valve thrombosis presented with a subtherapeutic INR value. Thrombolysis can be a useful option in the management of prosthetic valve thrombosis patients in a less resourceful country.
\end{abstract}

Keywords : Prosthetic valve thrombosis, stuck valve, Thrombolysis

\section{Introduction}

Prosthetic valve thrombosis (PVT) incidence is still high and contributes to significant late mortality post- valve surgery. PVT is one of the most dreaded complications of mechanical heart valves. The incidence varies depending on the type of mechanical heart valve and its incidence ranged from $0.5 \%$ to $8 \%$ per patient year in the aortic and mitral position and up to $20 \%$ in the tricuspid position. ${ }^{1}$ Guidelines are divided over the best line of therapy with the European Society of Cardiology recommends surgery for all, irrespective of clinical status, while the others (Society of heart valve diseases) recommend thrombolytic therapy for all patients without contraindications. ${ }^{2}$

In a poor clinical setup like Nepal; where the regular PT/ INR profile monitoring is at times difficult due to geographic and financial limitations. A number of patients often presents with bleeding complications as well as thrombotic complications especially with PVT. Due to the financial reasons, thrombolytic therapy still remains as the primary treatment for these cases of PVT.

We aimed to evaluate the clinical profile, management of patients and in hospital outcomes with PVT in Sahid Gangalal National heart Centre, Kathmandu, Nepal.

\section{Methods}

The study was a retrospective study with the data collected from hospital records of all patients diagnosed as PVT from Jan 2015 -Jan 2016 at Sahid Gangalal National Heart Centre. The study was conducted after approval from the hospital ethical review board. Details about the clinical profile, echocardiographic records and the mode of management, during the hospital stay and complications if noted was studied as per the records. Statistical analysis was done using SPSS version 20 and data were presented in the form of tables and diagrams. Appropriate statistical tests were carried out to compare the data, and a level of significance of 0.05 was used. Values were expressed as mean and standard deviation.

\section{Results:}

Twenty three patients with the confirmed diagnosis of PVT were admitted during the study period. The age group presenting with stuck valve ranged from (13 -49 years) with mean age of $35 \pm 10.0$ years. Majority of patients were female $(\mathrm{N}=12,52.2 \%)$. Sixteen patients ( $69.6 \%$ ) had INR value $<1.5$ while 7 patients ( $30.4 \%$ ) had a baseline INR $>1.5$ at presentation as shown in Table 1 . 


\begin{tabular}{|c|c|}
\hline \multicolumn{2}{|c|}{ Table 1. Baseline INR at presentation } \\
\hline Baseline INR & No. of patients \\
\hline$<1.5$ & $16(69.6 \%)$ \\
\hline$>1.5$ & $7(30.4 \%)$ \\
\hline
\end{tabular}

Most of the patients $(19,82.6 \%)$ presented within a week of onset of symptoms as shown in Table 2 . There was a wide range of duration of time to the presentation from the time of valve surgery. The mean time duration to presentation with stuck valve was 61 months with the earliest case presented at 2 months and the latest case as 156 months from the time of valve surgery. Most patients $(22,95.6 \%)$ presented with the complaint of shortness of breath while one patient presented with chest pain.

\begin{tabular}{|l|l|}
\hline \multicolumn{2}{|c|}{ Table 2. Duration of symptoms } \\
\hline $\begin{array}{c}\text { Duration of } \\
\text { symptoms }\end{array}$ & \multicolumn{1}{|c|}{ No of patients } \\
\hline$<1$ week & $19(82.6 \%)$ \\
\hline$>1$ week & $4(17.4)$ \\
\hline
\end{tabular}

All the patients had undergone valve replacement with mechanical prosthetic valves. St. Jude Bileaflet was the most commonly used. Twenty $(86.9 \%)$ patients were thrombolyed with injection Streptokinase ( 1.5 million units infusion over $12-18 \mathrm{hrs}$ ) while 3 patients $(13.1 \%)$ were treated with Injection tenectoplase (40 $\mathrm{mg}$ bolus i.v ). None of the patients were referred to surgical intervention post fibrinolytics or as a primary mode of therapy. Stuck prosthetic mitral valve was seen in $17(73.9 \%)$ patients while isolated stuck aortic valve was seen in $6(26.1 \%)$ patients. The mean gradient across stuck prosthetic mitral valve during admission ranged from 17 to $31 \mathrm{mmHg}$ with mean value of $24 \pm 4$ $\mathrm{mm} \mathrm{Hg}$. The mean gradient across stuck aortic valve ranged from 68 to $85 \mathrm{mmHg}$ with the mean of $77 \pm 8 \mathrm{mmHg}$. Significant echocardiographic reduction of valve gradients was seen in 21 patients $(91.3 \%)$ with the failure in $2(8.7 \%)$ patients. The mean gradient post- thrombolysis across mitral valve was $7.2 \pm 4$ $\mathrm{mmHg}$; while across aortic prosthetic valve was $21.2 \pm 11 \mathrm{mmHg}$. In hospital mortality was seen in $5(21.7 \%)$ patients. Among the deaths, 3 patients had reduction of valve gradients post thrombolysis and the cause of death was refratory heart failure. There was no in hospital complication like major bleeding or incidence of new stroke in patients treated with thrombolysis.

\section{Discussion:}

Prosthetic valve implantation is still on the rise since rheumatic heart disease is still prevalent. Many patients present with both late and early complications of valve replacement Common complications associated with prosthetic valve include bleeding complications, endocarditis, stuck prosthetic valve. PVT is defined as any thrombus, in the absence of infection, attached to or near an operated valve, occluding part of the blood flow or interfering with valvular function.

In a large study, $21 \%$ of cases of PVT occurred in the first month after heart valve replacement. ${ }^{3}$ Two major types of prosthetic heart valves exist: mechanical and bioprosthetic.
Mechanical prosthetic heart valves are more durable but also more thrombogenic than bioprosthetic valves. Although the profile of new generation mechanical bileaflet valves is largely superior to that of earlier generation prostheses (and thus associated with a lower occurrence of thromboembolic complications), localised regions of turbulent flow can still develop and lead to stasis and thrombus formation. In addition, the location of the prosthesis plays an important role in thrombogenicity. Obstruction of tricuspid mechanical prosthesis is 20 times more frequent than left-sided PVT. ${ }^{4}$ Similarly, mitral PVT is $2-3$ times more frequent than thrombosis of an aortic prosthesis. Interruption of oral anticoagulant treatment for anticipated non cardiac surgery and pregnancy represent high risk situations for patients with prosthetic valves. ${ }^{5}$

Diagnosis of PVT is based solely on clinical suspicion with left or right sided heart failure depending on the valve involved along with echocardiography, fluoroscopy and TEE examination. At times it is difficult to differentitate between thrombosis from pannus despite of all the investigation and usually those group with pannus have poor response and outcome to thrombolysis. Management of PVT is predominantly surgical intervention especially for left sided valves. Fibrinolytic therapy is an alternative to surgical treatment. ${ }^{6}$ It is considered the treatment of choice for tricuspid PVT. ${ }^{7}$ However, because of the high risk of cerebral thromboembolism during thrombolysis for left-sided PVT, its use is reserved mainly for high risk surgical candidates. ${ }^{8,9}$ In a review of 200 reported cases of left-sided PVT treated with thrombolysis, Lengyel et al. reported an initial success rate of $82 \%$ and a mortality of $6 \%$. In this study the incidence of complications was $12 \%$ for any kind of thromboembolism, $5 \%$ for Cerebrovascular accidents and $5 \%$ for hemorrhage.$^{10}$ Patients with mitral or aortic PVT documented by TEE with Doppler flow obstruction and functional class III or IV symptoms should be treated with fibrinolysis if the surgical risk is high and there is no contraindication. Surgical therapy is an alternative for patients in functional class III or IV not at high surgical risk.

In our retrospective analysis total of 23 patients were admitted with PVT with mean age at presentation being 35 years and mostly were female $12(52.2 \%)$ as compared to male $11(47.8 \%)$. While many studies have shown that women are more predisposed to PVT, in most studies from India men were more frequently involved. ${ }^{11}$ In our study, most common valve involved with obstruction was mitral $17(73.9 \%)$ patients followed by aortic valve $6(26.1 \%)$ patients. In a study by Gupta et al, $87.3 \%$ of the PVT episodes occurred in the mitral position. Several studies have confirmed that mitral PVT is 2-3 times more frequent than thrombosis of an aortic prosthesis. ${ }^{12}$

Successful thrombolysis as satisfying the strict criteria of "decrease in prosthetic valve gradient to baseline with normal prosthetic valve movement and in the absence of complications, need for surgery or death" was achieved in $21(91.3 \%)$ patients with a total mortality of ( $21 \%) 5$ patient as compared to a review of 200 patients by Lengyel et a ${ }^{13}$ reported an initial success rate of $82 \%$ and a mortality of $6 \%$.

The major limitation of the study is that it is only a single centre and retrospective study and this may not be the true representation of the whole community.

\section{Conclusion:}

Inadequate INR values and irregular follow up are the reasons for the high incidence of PVT. Thrombolysis can be a useful option in the management of PVT in our clinical setup. 


\section{References:}

1 Karthikeyan G, Math RS, Mathew N et al. Accelerated infusion of streptokinase for the treatment of left sided prosthetic valve thrombosis: A randomized controlled trial. Circulation 2009; 120:1108-14.

2. Vahanian, A.,Alfieri, O., Andreotti, F et al .2012 Guidelines on the management of valvular heart disease. European heart journal,2012;33(19): 2451-96.

3 Durrleman N, Pellerin M, Bouchard D, et al. Prosthetic valve thrombosis: twenty year experience at the Montreal Heart Institute. J Thorac Cardiovasc Surg 2004;127:1388-92.

4 Thorburn CW, Morgan JJ, Shanahan MX, Chang VP. Long-term results of tricuspid valve replacement and the problem of the prosthetic valve thrombosis. Am J Cardiol 1983;51:1128-32.

5 Gohlke-Bärwolf C. Anticoagulation in valvar heart disease: new aspects and management during non-cardiac surgery. Heart 2000;84:567-72

6 Luluaga IT, Carrera D, D'Oliveira J, et al . Successful thrombolytic therapy after acute tricuspid valve obstruction. Lancet 1971;1: 1067-8.

7 Villanyi J, Wladika ZS, Bartek I,et al. Diagnosis and treatment of tricuspid mechanical prosthetic valve dysfunction . Eur Heart J 1992;13(Suppl):374.

Cite this article as: Anish Hirachan, Madhu Roka, Dipanker Prajapati,et al. Prosthetic valve thrombosis in a tertiary cardiac centre.Nepalese Heart Journal 2017; 14(1): 9-11
8 Birdi I, Angelini GD, Bryan AJ. Thrombolytic therapy for left-sided prosthetic heart valve thrombosis. J Heart Valve Dis 1995;4:154 -9.

9 Forster T, Kardos A, Varga A, et al . Systemic thrombolysis in acute prosthetic valve thrombosis. Orv Hetil 1991; 132:2323-5.

10 Lengyel M, Wladika ZS, Borbola J, et al . The role of transesophageal echocardiography in the fibrinolytic treatment of mitral mechanical prosthetic valve thrombosis. Orv Hetil 1994;135:955- 60

11 Heras M, Chesebro JH, Fuster V, et al. High risk of thromboemboli early after bioprosthetic cardiac valve replacement. J Am CollCardiol 1995;25: 1111-9

12 Tischler MC, Lee RT, Kirshenbaum JM. Successful treatment of prosthetic tricuspid valve thrombosis with short-course recombinant tissue-type plasminogen activator. Am Heart J 1990; 120:975-8.

13 Lengyel M, Fuster V, Keltai M, et al. Guidelines for management of left-side prosthetic valve thrombosis: a role for thrombolytic therapy. Consensus Conference on prosthetic valve thrombosis. J Am Coll Cardiol 1997; 30:1521-6. 